\title{
Centre turns away from healing herbs
}

US research hub on complementary and alternative medicine shifts towards symptom management.

A decade ago, US National Institutes of Health (NIH) director Harold Varmus was invited to quit when he opposed a senator's plans to elevate a small NIH office into a research centre for testing the validity of alternative therapies.

Having grown from those modest beginnings, the National Center for Complementary and Alternative Medicine (NCCAM) in Bethesda, Maryland, celebrates its tenth anniversary this week. It still draws fire from traditional scientists, who complain that by the very act of studying therapies outside the realm of conventional medicine, it has legitimized them.

But, many of the centre's clinical trials have ended up disproving alternative therapies rather than endorsing them. One study published in July 2005 (R. B. Turner et al. N. Engl. J. Med. 353, 341-348; 2005) showed that the herb echinacea neither prevented nor relieved the symptoms of rhinovirus infections, the most common cause of the 'common cold'; sales of echinacea fell markedly thereafter (see graphic). "We are in fact unbiased," says Josephine Briggs, who took over as centre director early last year, having overseen the NIH's kidney research for almost a decade until 2006. "We are directing research that will be rigorous."

In 2007, 38\% of Americans said they had turned to alternative treatments at least once over the previous 12 months, spending US $\$ 33.9$ billion on a gamut of therapies from acupuncture to herbal remedies to yoga. Dwarfed by other research powerhouses on the NIH's Bethesda campus, the NCCAM this year spent $\$ 125$ million studying these treatments, or about one-third of the NIH's total investment in alternative therapies; the rest is spent by other institutes and centres, particularly the National Cancer Institute.

Briggs and others say that the goal is to provide hard data on alternative therapies, regardless of whether that data debunks or affirms any given treatment. "One of [NCCAM's] critical roles is to actually weed out the snake oil, which I am sure there is quite a bit of," says Richard Davidson, a neuroscientist and NCCAM grantee at the University of Wisconsin, Madison. His work on the effects of meditation on the brain and peripheral biology has been published in mainstream journals such as The Proceedings of the National Academy of Sciences, PLoS Biology and The Journal of Neuroscience.

Many US researchers still say such funding is a waste of time and money. "You are doing scientific research on treatment modalities that are not being used or promoted by science-based practitioners in the first place," says Steven Novella, a neurologist at Yale University in New Haven, Connecticut. "They never abandon a treatment because the scientific evidence shows that it doesn't work. So what's the point?"

Briggs says that she would like to see the focus of the institute move away from overly "optimistic" attempts to cure chronic diseases, a trend she saw in grant applications after assuming the centre director job. "Investigators entered the project thinking a herbal compound might change diabetes or cancer," she says. "The main way I'm trying to adjust our portfolio is greater focus on symptom management, particularly greater focus on pain", for which many use alternative therapies.

Indeed, the list of "promising leads" flagged in the centre's draft strategic plan for the next five years is weighted towards pain management and mind-body medicine and silent on herbal therapies.

Briggs is also pushing an increased emphasis

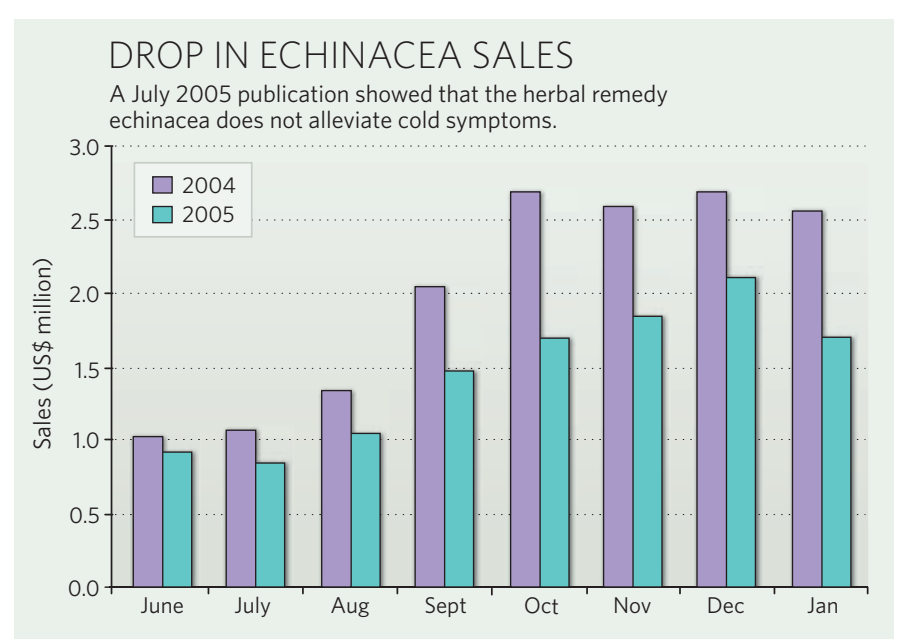

on basic and animal studies of the physiological mechanisms underlying alternative remedies. In its first decade, along with the echinacea work, the institute funded costly clinical trials studying whether St John's wort could relieve depression and, with the National Cancer Institute, whether vitamin $\mathrm{E}$ and selenium could prevent prostate cancer, among other studies. The results were resoundingly negative. Briggs concluded that the NCCAM needs to invest in fundamental work on natural products "before we invest more in clinical trials".

The centre "is increasingly defining a mission for itself that makes sense scientifically", says Bruce Rosen, an NCCAM grantee at Harvard Medical School in Boston, Massachusetts, who studies acupuncture's effect on brain function.

Briggs's approach has earned the respect of even the institute's fiercest critics. "I'm encouraged by Dr Briggs's receptiveness to comments and criticisms, and her commitment to altering the research priorities of the NCCAM," says Donald Marcus, an immunologist at Baylor College of Medicine in Houston, Texas. "My concern is the political constraints under which she operates."

Marcus and Novella are members of the Institute for Science in Medicine, a group of physicians and scientists newly set up to fight government policies promoting alternative medicine. He contends that the entire NCCAM enterprise "has been a remarkable waste of money", driven by Senator Tom Harkin (Democrat, Iowa), who authored the 1998 legislation that established the centre. "The best thing they could do with the NCCAM is to dissolve it," Marcus says. "But that's not going to happen. Harkin's too powerful."

A decade after the NCCAM's birth, that power remains on display: Harkin and others have inserted provisions in healthreform bills in both houses of Congress mandating that insurers reimburse state-licensed alternative medicine providers.

Meredith Wadman 